\title{
Needle aponeurotomy for dupuytren's contracture of hand with extended physical therapy and serial intralesional steroid injections
}

\author{
Soni R.K. ${ }^{1}$, Malviya V.K. ${ }^{2}$ \\ ${ }^{1}$ Dr. Ram Kripal Soni, Assistant Professor, Department of Orthopaedic, ${ }^{2}$ Dr. Vikas Kumar Malviya, Associate Professor, \\ Department of General Surgery, Both author are affiliated with L.N. Medical College, Bhopal, MP, India.
}

Corresponding Author: Dr. Vikas Kumar Malviya, Associate Professor, Department of General Surgery, author is affiliated with L.N. Medical College Bhopal (MP) India. E-mail: drvikas07@gmail.com

\begin{abstract}
Background: Dupuytren's disease is common benign proliferative disorder of the palmer fascia and is a part of a group of fibromatosis that includes planter fibromatosis (Ledderhose disease) and penile fibromatosis (Peyronie's disease). It tends to present in sixth and seventh decade of life but can present earlier or later. Method: we recruited eleven patients with Dupuytren's contracture of hand in the present study. Percutaneous release of the Dupuytren's band was performed under local anesthetic agent with an 18 Gauze needle in outpatient department. Postoperatively all patients underwent the programme of extended vigorous physical therapy of the hand and series of triamcinolone injections at 4 monthly interval for 1 year. Result: In our study all patients were males in the age range of 48 to 78 years. Commonly involved finger was the ring finger in six patients followed by little finger in three and middle finger in two. Nine patients had right finger affected and in rest two left side fingers were affected. All patients did well and there was no recurrence of contracture in any patients during the study period. One patient experienced unexplained chronic pain in the finger. Postoperatively range of motion improved significantly after 18 months of follow-up. Conclusion:Percutaneous needle aponeurotomy with extended post-operative physical therapy and serial 4 monthly intralesional steroid injections in Dupuytren's contracture is reliable and relatively simple to perform compared to partial aponeurectomy. This regime of treatment could be seen as a serious alternative for selected cases.
\end{abstract}

Keywords: Percutaneous needle fasciotomy, Dupuytren's contracture, Needle aponeurotomy, Intralesional corticosteroid injection, Extended physical therapy hand.

\section{Introduction}

Baron Guillaume Dupuytren first correctly identified the condition that bears his name as a chronic fibrotic contracture of the palmer fascia on 1833 [1]. Dupuytren's contracture is an inherited disease of progressive fibrous tissue contracture of the palmer fascia of hand [2]. Contracture forms when the palmer fascia begins to get thicken and tighten, causing finger to bend. It shows up as a thick nodule or a short cord in the palm of hand under the skin, just below the commonly affected ring finger.

More nodules form and the tissue thicken and shorten until the finger cannot be fully straightened [3]. Classically nodule precedes development of a cord [4]. In an epidemiological study, $19.2 \%$ males and $4.4 \%$ females were affected by Dupuytren's disease [5]. The

Manuscript Received: $10^{\text {th }}$ August 2019

Reviewed: $20^{\text {th }}$ August 2019

Author Corrected: $25^{\text {th }}$ August 2019

Accepted for Publication: $29^{\text {th }}$ August 2019 prevalence increases with age from $7.2 \%$ among males in the age group $45-49$ years up to $39.5 \%$ in those $70-74$ years old [5]. Men typically present earlier (mean age55 years) than women (10 years later) and have much more severe disease [5]. The overall incidence of Dupuytren's disease (DD) in the UK is around $4 \%$, rising to about $20 \%$ in those over 65 years [6]. Generally females have a slightly higher incidence of proximal inter phalangeal joint contracture affecting post-menopausal women.

They also have less severe contractures on presentation and a slower progression thereafter [7]. Main presenting feature of the disease is painless increasing loss of range of motion of the affected finger along with loss of dexterity and hand getting caught when trying to place in a pocket. Risk factors of Dupuytren's disease are age of more than 40 years, male gender, scandivanian heritage, family history, smoking, alcohol intake and diabetes mellitus [8]. Although Epilepsy and anti- 


\section{Original Research Article}

epileptic medications are widely described in the literature to be one of the risk factor for the disease but that was not the case according to Geogheagan et al [9]. There are few objective staging systems to assess severity of Dupuytren's disease. Currently the degree of contracture in an affected digit is used solely as a measure of the disease severity [10]. Disease progression is classified using a grading system. Grade 1 disease presents as a thickened nodule and a band in the palmar aponeurosis; this band may progress to skin tethering, puckering, or pitting. Grade 2 presents as a peritendinous band, and extension of the affected finger is limited. Grade 3 presents as flexion contracture [4].

Radiation therapy for early Dupuytren's contractures in adults has been suggested. This involves directing low energy X-rays at the affected tissue [11, 12]. Intralesional corticosteroid injections have been shown to reduce the need for surgery [13]. Surgery is indicated when metacarpophalangeal joint contractures reach 30 degrees, or if any degree of proximal interphalangeal joint contracture is present. The technique of percutaneous needle fasciotomy was first described by Henry Kline in 1787, but it took a French Rheumatologist, Dr Lermusiaux in the 1970's to popularize the technique [14].

The risks of infection, hematoma formation and digital nerve injury are lower with needle aponeurotomy compared to open fasciectomy [15]. This technique is also significantly more cost-effective than open fasciectomy and collagenase injections [15].

Although there have been several studies in past on percutaneous needle fasciotomy, but this is the first study with percutaneous needle fasciotomy under local anaesthetic with extended vigorous physical therapy and repeated intralesional steroid injections post operatively.

\section{Method}

Place of study: J K Hospital associated with L.N. Medical College Bhopal (M.P.)

Type of study: Prospective study

Sampling method: Consecutive

Sample collection: Eleven adults with diagnosis of Dupuytren's contracture of hand with grade three categories, involving 25 degrees or more of the MCP joint of the digit and not more than 5 degrees of PIP joint were included in this study [4]. Percutaneous release of the Dupuytren's band under local anesthetic with an 18 Gauze needle was done in outpatient department under local anaesthetics agent.We first counsel the patient and explain what the procedure entails in detail including its risks and benefits. We also explain the programme of extended vigorous physical therapy of the hand and series of triamcinolone injections post operatively at 4 monthly interval for 1 year. After this an informed consent of patient was obtained. All the procedures were performed in the same manner, at the same facility and by two surgeons. All the relevant details of patients were tabulated using specified Performa. History of diabetes and alcohol intake was also recorded. Clinical details of the patient were also recorded like side of the hand, number of fingers involved, severity of contracture at MCP and PIP joint, active range of motion at MCP joint and PIP joint and duration of the contracture.

\section{Inclusion and exclusion criteria}

Inclusion criteria: 1. Patients with grade three palpable dupuytren cord. 2. Patients with flexion contracture at MCP joint of 25 degrees or more. 3. Elderly patient with associated co morbid conditions which precluded them from having general or regional block anesthesia.

Exclusion criteria: 1. Patients with bilateral disease and ectopic lesion outside the palm. 2. PIP joint contracture of more than 5 degrees.

Procedure: The patient's forearm was prepared and was draped with an arm cover according to the standard procedure for minor surgery. A $5 \mathrm{ml}$ syringe and 25 gauge needle was used and 5 milliliters of $0.5 \%$ lignocaine was injected locally. Under local anesthetic we inserted an 18 gauzeneedle in slight oblique fashion under the skin and above the cord which is divided with the help of bevel of the needle. Needle is introduced in a slight oblique fashion. Bevel of the needle is used as a knife. Sectioning is achieved by moving the needle in sawing motion against the fibrous band.

This movement is repeated several times until the band breaks, or until partial sectioning has been achieved and the finger can be extended causing the band to snap. We than straighten the finger passively and the remaining fibers of the cord are ruptured. This allows the finger to straighten but the diseases tissue is not removed. Depending on the severity of the condition some individuals may require more than one session, particularly if there is contracture of the PIP joint.Procedure time ranged from 35 to 45 minutes and is done as an outpatient procedure. A pressure dressing is applied and patient is advised to keep hand elevated. The pressure dressing is than removed and a small adhesive dressing is applied after 48 hours. Patient is 


\section{Original Research Article}

advised to avoid strenuous gripping for about 10 days. After this time patient is advised to return to activities as tolerated and to use hand splint for night use for 6 months. This is to keep the joint straight and prevent new contracture from forming.

Patients were assessed at one week follow-up after the procedure, at which time joint movements, flexor tendon and nerve function and any side effects of the given treatment were recorded. Patients were examined at 2 weeks, 6 weeks, 4 months, 8 months, 12 months and every 4 months thereafter. The intralesional triamcinolone injections were done at every 4 months interval after the procedure.

Rehabilitation begins couple of days after the procedure. Regular physical therapy is the key for the success of this procedure which prevents the recurrence of the disease. Patient is taught gentle regular stretching exercises of the finger, which patient must continue at home for a week than patient progresses to a program of vigorous stretching exercises which he or she must continue for 6 weeks. These exercises are important in limiting the buildup of scar tissue, preventing the return of contracture and in getting the most benefit from the surgery.

When recovery is well underway, patient can stop going to physiotherapy department but he or she will be in charge of independently doing exercises as part of an ongoing home programme.

Patient underwent intralesional series of $40 \mathrm{mg}$ Triamcinolone injections post operatively at 4 monthly intervals for one year period. We recommend strict adherence to the designed protocol and the importance of intralesional triamcinolone acetonide injections into nodules and not beneath them.

\section{Result}

Between August 2015 and February 2019 eleven patients with Dupuytren's contracture were treated in our hospital with 25 degrees or more of flexion contracture at metacarpophalangeal joint (MCP Joint) of the involved finger.

Table-1: Age distribution.

\begin{tabular}{|c|c|}
\hline Age group (years & Number of patients \\
\hline $48-58$ & 1 \\
\hline $58-68$ & 6 \\
\hline $68-78$ & 4 \\
\hline
\end{tabular}

In our study all patients were males in the age range of 48 to 78 years. Most of the patients belonged to 58 to 68 years of age group.

Table-2: Fingers affected and side of upper limb.

\begin{tabular}{|c|c|}
\hline Finger involved & Number of patients \\
\hline Little finger & 3 (Right2. Left 1) \\
\hline Ring finger & 6 (Right 5. Left 1) \\
\hline Middle finger & 2 (both right) \\
\hline
\end{tabular}

The most commonly involved finger was the ring finger followed by little and middle fingers. Right side fingers were most commonly affected.

Table-3: Risk factors.

\begin{tabular}{|c|c|c|c|c|}
\hline Family History & Smoking & Alcohol intake & Diabetes & Epilepsy. \\
\hline 4 & 2 & 4 & 7 & 1 \\
\hline
\end{tabular}

Majority patients in our series were Diabetic which is clearly one of the major risk factor for development of the Dupuytren's disease. 
Original Research Article

Table 4: Severity of Flexion contracture at MCP joint and Finger involved pre operatively

\begin{tabular}{|c|c|c|c|c|c|}
\hline $\begin{array}{c}\text { Finger } \\
\text { Involved }\end{array}$ & $\begin{array}{c}\mathbf{2 5} \text { to } 40 \\
\text { degrees } \\
\text { at MCPJ }\end{array}$ & $\begin{array}{c}\text { 41 to 55 degrees } \\
\text { at MCPJ }\end{array}$ & $\begin{array}{c}\text { 56 to 70 degrees } \\
\text { At MCPJ }\end{array}$ & $\begin{array}{c}\text { PIP joint } \\
\text { involvement }\end{array}$ & $\begin{array}{c}\text { Presence of } \\
\text { Dupuytren's Band }\end{array}$ \\
\hline Little & 2 & 1 & 0 & 1 & 2 \\
\hline Ring & 3 & 2 & 1 & 1 & 4 \\
\hline Middle & 2 & & & & 1 \\
\hline
\end{tabular}

One patient with Ring finger involvement had 60 degrees of contracture at MCP joint. This pt also had PIP joint involvement and 5 degrees of PIP joint contracture.

Table-5: Residual contracture at MCPJ in fingers after the operation and during the last follow-up.

\begin{tabular}{|c|c|c|c|}
\hline Finger involved & 0 to 15 degrees & 16 to 30 degrees & 31 to 45 degrees. \\
\hline Little & 3 & 0 & 0 \\
\hline Ring & 5 & 1 & 0 \\
\hline Middle & 2 & 0 & 0 \\
\hline
\end{tabular}

There was one patient with residual flexion contracture at MCP joint of ring finger of 20 degrees post operatively. This did not progress further during the follow-up period.

Table-6: Outcome and complications.

\begin{tabular}{|c|c|c|}
\hline 1 & Successful & 10 \\
\hline 2 & Recurrence & 0 \\
\hline 3 & Infection & 0 \\
\hline 4 & Nerve injury & 0 \\
\hline 5 & Tendon Injury & 1 \\
\hline 6 & Chronic pain & 1 \\
\hline 7 & Residual contracture at MCPJ & 0 \\
\hline 8 & Skin tearing. & 0 \\
\hline
\end{tabular}

Most of our patients were satisfied with the treatment with good functional improvement in their operated finger. $86 \%$ of patients said that they would undergo the treatment again if necessary.

\section{Discussion}

Dupuytren's contracture is a benign, slowly progressive condition of unknown origin [16]. The disease is characterized by a thickening of the connective tissue in the palm of the hand, leading to difficulties extending the fingers [17]. Although the origin of the condition is unclear, a significant majority of patients relate a positive family history, which suggests a possible genetic influence [1].

Men are more likely to be affected than women, and the symptoms of the disease are more severe in older men and in people of northern European descent [15]. Most patients with Dupuytren's contracture had involvement of both hands. In unilateral cases the right side is more typically affected than the left. The most commonly involved digit is the ring finger, followed by the little finger and then the middle finger. The index finger and thumb are typically spared. Our study focuses upon the effectiveness and safety of serial post procedure intralesional steroid injection following needle aponeurotomy combined with extended physical therapy.

Percutaneous fasciotomy or needle aponeurotomy is done in early stages of the disease or in elderly patients who have other health issues that might make open fasciectomy under general anesthesia or under regional block too risky. This is done mainly in patients with 


\section{Original Research Article}

grade 3 contracture who have a palpable cord lying beneath the skin. Patients with less severe disease and or those with metacarpophalangeal joint contracture benefited most from this procedure. Since there is no incision there is no chance of additional contracture from scar tissue formation.

General believe is that needle fasciotomy is best suited for well-informed elderly patients with relatively mild contractures and for those who are willing to accept a higher recurrence risk of $85 \%$ in the context of a lower complication rate, fast recovery and minimal invasiveness [18]. This high recurrence rate may be due to the fact that the diseased tissue remains and can continue to contract.

However in our experience with this small series we have not encountered any recurrence due to extended physical therapy and serial intralesional steroid injections post operatively during the short follow-up period. We employed extended hand therapy as a potential means of sustaining effectiveness [15,19]. Other advantage of our regime is that it can be repeated in recurrent disease [20]. Molenkemp et al also experienced similar advantage with needle aponeurotomy.

Chronic flexion contracture of the proximal interphalangeal (PIP) joint presents a common yet challenging problem to hand surgeons [21]. Two patients had a PIP joint contracture and, even though the Dupuytren's band was treated at the MCP joint level, both patients retained a straight PIP joint at one year follow-up. Skov et al also reported similar outcome at the level of PIP joint [15]. However one patient who had MCP J contracture of 60 degrees Pre-operatively could not improve fully and had residual contracture of 20 degrees post operatively but his PIP joint contracture of 5 degrees improved to normal. Although PIP joint involvement is much more common in females [6]. but both our patients were males. This may be due to the fact that it is a very small series.

The other noticeable observation in our study was the disappearance of Dupuytren band in 7 out of 11 patients in our study suggested that reduced tension in the cord might cause apoptosis of myofibroblasts where by myofibroblasts-rich nodule fail to persist, and the result of our study lend support to this theory [22].

Other suggestion is that diminishes tension in a locally treated ruptured Dupuytren cord lead to resorption of pathological collagen in some patients and the recurrent cord is formed de novo [23].
Series of intralesional steroid injection was given to all patients post operatively at 4 monthly intervals; first injection was given 4 months post procedure. One patient developed local depigmentation and dermal atrophy at the injection site from collagen degradation. This has been observed by others as well [24].

This complication resolved within 6 months period. All eleven patients received four serial intralesional steroid injections except three patients who received three and two injection each. These were the patients who were recruited towards the later part of the study therefore could not complete all four injections before the end of study date.

Reported complications from Needle aponeurotomy are at a low rate and are minor.Molenkamp et al reported a low complication rate $(12 \%)$; the most common complication was skin tears, which occurred in $9 \%$ of subjects [20]. Nydick et al and Pess et al, also reported only minor complications after NA, and skin tearing was the most common $[25,26]$. On the other hand Stromberg and Ebsen $\mathrm{t}$ al, reported high rate of skin tears at 38\% with needle aponeurotomy [27]. Other potential complications are nerve injury, infection and hematoma formation.

These complications are much higher with open procedure, than with needle Aponeurotomy [28]. We however did not encounter any such complications in our short series.Major complication of nerve laceration is rare and there was no such complication in this study.

Main weakness of our study is that it is a very small series with relatively short follow-up.In this small consecutive series of 11 patients, all but one patient retained a straight finger throughout the follow-up period. We also observed good results on patientsreported outcome measures and although subjective, it ultimately provides insight into patient experience and perceived view of effectiveness.

These patients warrant longer follow up in a larger series, but the recurrence rate at 18 months clearly underscore lower recurrence rate than reported in the literature previously [18].

\section{Conclusion}

Needle aponeurotomy with extended physical therapy, serial intralesional steroid injections for dupuytren contracture of hand is done as a day case procedure and gives fairly satisfactory result in selected patients. It has a lower complication rate and quicker recovery when 


\section{Original Research Article}

compared with open fasciectomy and can be therefore offered to patients as a first-line treatment.This procedure is well-tolerated, minimally invasive and is substantially low cost treatment.

\section{What this study adds to existing knowledge?}

This is the first study of its kind describing needle aponeurotomy for Dupuytren's contracture of hand with extended physical therapy and serial intralesional steroid injections. There is no such study in the literature described previously.

\section{Author's contribution}

Dr. Ram Soni formulated the aims \& objectives with study design and supervised for study

Dr. Vikas Kumar Malviya contributed to the preparation of the manuscript and data analysis.

Conflict of interest: None declared.

Funding: Nil, Permission from IRB: Yes

\section{References}

1. Dupuytren G. Permanentre retraction of the fingers produced by an affection of the palmar fascia. Lancet. $1834 ; 2: 222-225$.

2.Hu FZ, Nystrom A, Ahmed A, Palmquist M, Dopico $\mathrm{R}$, Mossberg I, et al. Mapping of an autosomal dominant gene for Dupuytren's contracture to chromosome 16q in a Swedish family. Clinic Gen. 2005; 68(5): 424-429. doi: 10.1111/j.1399-0004.2005. 00504.x

3. Elliot D. The early history of contracture of the palmar fascia. Part 1: The origin of the disease: the curse of the Mac Crimmons: the hand of benediction: Cline's contracture. J Hand Surg Br. 1988;13(3): 246253. doi:10.1016/0266-7681(88)90078-2

4. Townley WA, Baker R, Sheppard N, Grobbelaar AO. Dupuytren's contracture unfolded. BMJ. 2006;332 (7538): 397-400. doi:10.1136/bmj.332.7538.397

5.Gudmundsson KG, Arngrímsson R, Sigfússon N, Björnsson A, Jónsson T. Epidemiology of Dupuytren's disease: clinical, serological, and social assessment. The Reykjavik Study. J Clin Epidemiol. 2000; 53(3):291296. doi:10.1016/s0895-4356(99)00145-6

6. Early PF. Population studies in Dupuytren's contracture. The Journal of Bone and Joint Surgery. British volume. 1962; 44 (3): 602-613.
7. Stahl S, Calif E. Dupuytren's palmar contracture in women. Isr Med Assoc J. 2008;10(6):445-447.

8. Burge P, Hoy G, Regan P, Milne R. Smoking, alcohol and the risk of Dupuytren's contracture. J Bone Joint Surg Br. 1997;79(2):206-210. doi:10.1302/0301620x.79b2.6990

9.Geoghegan JM, Forbes J, Clark DI, Smith C, Hubbard R.Dupuytren's disease risk factors. J Hand Surg Br. 2004;29(5):423-426. doi:10.1016/j.jhsb.2004. 06.006

10. Hindocha S, Stanley JK, Watson JS, Bayat A. Revised Tubiana's staging system for assessment of disease severity in Dupuytren's disease-preliminary clinical findings. Hand (NY). 2008; 3(2): 80-86. doi: 10. 1007/s11552-007-9071-1. Epub 2007 Sep 11.

11. Finney R. Dupuytren's contracture. Br J Radiol. 1955; 28 (335): 610-614. doi:10.1259/0007-1285-28$335-610$

12. Lukacs S, Braun-Falco O, Goldschmidt H. Radiotherapy of benign dermatoses: indications, practice, and results. J Dermatol Surg Oncol. 1978;4(8): 620-625. doi:https: //doi.org/ 10.1111/j. 1524-4725. 1978. tb00 512.x

13.Ketchum LD, Donahue TK. The injection of nodules of Dupuytren's disease with triamcinolone acetonide. J Hand Surg Am. 2000;25(6):1157-1162. doi: 10.1053/ jhsu. 2000.18493

14. Lermusiaux JL, Lellouche H, Badois JF, Kuntz D. How should Dupuytren's contracture be managed in 1997? Rev Rhum Engl Ed. 1997;64(12):775-776.

15. Skov ST, Bisgaard T, Søndergaard P, Lange J. Injectable Collagenase Versus Percutaneous Needle Fasciotomy for Dupuytren Contracture in Proximal Interphalangeal Joints: A Randomized Controlled Trial. J Hand Surg Am. 2017;42(5):321-328.e3. doi: 10.1016 /j.jhsa. 2017.03.003.

16. Shih B, Bayat A. Scientific understanding and clinical management of Dupuytren disease. Nat Rev Rheumatol. 2010;6(12):715-726. doi: 10.1038/nrrheum. 2010. 180. Epub 2010 Nov 9.

17. Hurst LC, Badalamente MA, Hentz VR, Hotchkiss RN, Kaplan FT, Meals RA, et al. Injectable collagenase clostridium histolyticum for Dupuytren's contracture. N Engl J Med. 2009;361(10):968-979. doi: 10.1056/ NEJ Moa 0810866. 


\section{Original Research Article}

18. van Rijssen AL, ter Linden H, Werker PM. Fiveyear results of a randomized clinical trial on treatment in Dupuytren's disease: percutaneous needle fasciotomy versus limited fasciectomy. Plast Reconstr Surg. 2012; 129(2): 469-477. doi: 10.1097/PRS.0b013e31823aea95.

19. Mickelson DT, Noland SS, Watt AJ, Kollitz KM, Vedder NB, Huang JI. Prospective randomized controlled trial comparing 1- versus 7-day manipulation following collagenase injection for dupuytren contracture. J Hand Surg Am. 2014; 39(10):1933-1941. e1.doi: 10.1016/j.jhsa.2014.07.010.Epub 2014 Sep 4.

20. Molenkamp S, Schouten TAM, Broekstra DC, Werker PMN, Moolenburgh JD. Early Postoperative Results of Percutaneous Needle Fasciotomy in 451 Patients with Dupuytren Disease. Plast Reconstr Surg. 2017;139(6):1415-1421.doi:10.1097/PRS.000000 0000 003357.

21. Houshian S, Jing SS, Chikkamuniyappa C, Kazemian GH, Emami-Moghaddam-Tehrani M. Management of posttraumatic proximal interphalangeal joint contracture. J Hand Surg Am. 2013;38(8):16511658. doi: 10.1016/j.jhsa.2013.03.014. doi:10.1016/j. jhsa. 2013.03.014

22.Verjee LS, Midwood K, Davidson D, Essex D, Sandison A, Nanchahal J. Myofibroblast distribution in Dupuytren's cords: correlation with digital contracture. J Hand Surg Am. 2009;34(10):1785-1794. doi: 10.1016/j. jhsa.2009.08.005. Epub 2009 Nov 11.
23. Strömberg J, Vanek P, Fridén J, Aurell Y. Ultrasonographic examination of the ruptured cord after collagenase treatment or needle fasciotomy for Dupuytren's contracture. J Hand Surg Eur Vol. 2017;42 (7): 683-688. doi: 10.1177/1753193417711594. Epub 2017 Jun 6.

24. Ketchum LD, Donahue TK. The injection of nodules of Dupuytren's disease with triamcinolone acetonide. J Hand Surg Am. 2000;25(6):1157-1162. doi:10.1053/jhsu.2000.18493

25. Nydick JA, Olliff BW, Garcia MJ, Hess AV, Stone JD. A comparison of percutaneous needle fasciotomy and collagenase injection for dupuytren disease. J Hand Surg Am. 2013;38(12):2377-2380. doi: 10.1016/j.jhsa. 2013. 08.096. Epub 2013 Sep 20.

26. Pess GM, Pess RM, Pess RA. Results of needle aponeurotomy for Dupuytren contracture in over 1,000 fingers. J Hand Surg Am. 2012;37(4):651-656. doi: 10. 1016/j.jhsa.2012.01.029.

27. Strömberg J, Ibsen-Sörensen A, Fridén J. Comparison of Treatment Outcome After Collagenase and Needle Fasciotomy for Dupuytren Contracture: A Randomized, Single-Blinded, Clinical Trial With a 1Year Follow-Up. J Hand Surg Am. 2016;41(9):873-880. doi: 10.1016/j.jhsa.2016.06.014. Epub 2016 Jul 27.

28. Denkler K. Surgical complications associated with fasciectomy for dupuytren's disease: a 20-year review of the English literature. Eplasty. 2010;10:e15.

\section{How to cite this article?}

Soni R.K, Malviya V.K.Needle aponeurotomy for dupuytren's contracture of hand with extended physical therapy and serial intralesional steroid injections.Surgical Update: Int J surg Orthopedics. 2019;5(4):239-245.doi:10.17511/ijoso. 2019.i04.02 